\title{
Spectrum-based Phase Mapping of Apatite and Zoned Monazite Grains Using Principal Component Analysis
}

\author{
Stephen M. Seddio ${ }^{1}$ \\ ${ }^{1}$ Thermo Fisher Scientific, Madison, WI, USA
}

EDS (energy-dispersive spectroscopy) X-ray mapping typically requires the microanalyst to make tradeoffs between minimizing interaction volume size (determined by accelerating voltage), collecting a statistically meaningful number of counts above background (determined by beam current and/or counting time), selecting the elements for which to analyze in the mapping run, and avoiding beam damage to the sample. These trade-offs may produce confusing results, especially when a mapped sample contains multiple phases with similar compositions. X-ray maps are collected by assigning counts from a region of an EDS spectrum to a pixel in the map. Although contrast enhancements and filters can be applied to X-ray maps to suppress the background and highlight areas of varying concentrations, they fail to eliminate the confusion presented by interfering X-ray lines and multiple phases with similar compositions. However, by acquiring an image cube with an EDS spectrum at every pixel and comparing the mapped spectra to one another using principal component analysis, phases, even with similar compositions, can be readily distinguished even at low accelerating voltages.

A rock sample containing accessory monazite ([La, Ce, $\mathrm{Pr}, \mathrm{Nd}, \mathrm{Th}] \mathrm{PO}_{4}$ ) was mounted in thick section, carbon coated, and examined in an FESEM. EDS data were processed using the Thermo Scientific ${ }^{\text {TM }}$ NORAN System 7. EDS spectral imaging was done at 5 and $15 \mathrm{kV}$ accelerating voltages. Phases were identified using COMPASS ${ }^{\text {TM }}$ spectral phase mapping, which identifies unique phases based on the principle component analysis of the EDS spectrum at each pixel [1,2].

In Figs. 1 and 2, an apatite $\left(\mathrm{Ca}_{5}\left[\mathrm{PO}_{4}\right]_{3}[\mathrm{~F}, \mathrm{Cl}, \mathrm{OH}]\right)$ grain is partially included in a monazite grain. In BSE (backscattered electron) imaging done at $15 \mathrm{kV}$ (Fig. 1a), transmission through thin phases on the sample surface (e.g., silica grain just left of image center) is evident. Imaging at lower accelerating voltage (e.g., $5 \mathrm{kV}$; Fig. 2a) produces an image and X-ray maps more representative of the sample surface. In the $5 \mathrm{kV} \mathrm{O}$ and $\mathrm{P} \mathrm{K} \alpha \mathrm{X}$-ray maps (e.g., Fig. 2c), apatite and monazite are indistinguishable, even after a 2.5 hour acquisition. At $5 \mathrm{kV}$, the Ca K-lines are too weakly fluoresced at to produce a meaningful map. If an analyst were to map this sample and not include a light REE in the setup, monazite would likely be misidentified as apatite. However, after only 7.5 minutes of acquisition time, COMPASS successfully distinguishes the phases (Fig. 2c). Additionally, spectral imaging of the monazite grain in Fig. $1 \mathrm{~b}$, done at $15 \mathrm{kV}$, reveals that the grain is zoned and has a partial rim, $<1 \mu \mathrm{m}$ wide, that contains more Th relative to the interior. Principal component analysis is able to distinguish the Th-rich rim at $5 \mathrm{kV}$ as well (Fig. 2b). However, the magnification at which the spectral imaging is done must be increased to accommodate the weak fluorescence of Th M $\alpha$ (2.996 keV) at $5 \mathrm{kV}$ (Fig. 3).

Principal component analysis is an important tool for clarifying otherwise confusing X-ray maps. Using spectral imaging with principal component analysis can provide higher confidence identification of phases in less time than traditional EDS and WDS elemental mapping. 


\section{References}

[1] Keenan et al., Method of Multivariate Spectral Analysis. Patent 6,675,106 B1. 06 Jan. 2004.

[2] Keenan et al., Apparatus and System for Multivariate Spectral Analysis. Patent 6,675,106 B1. 06 Jan. 2004.
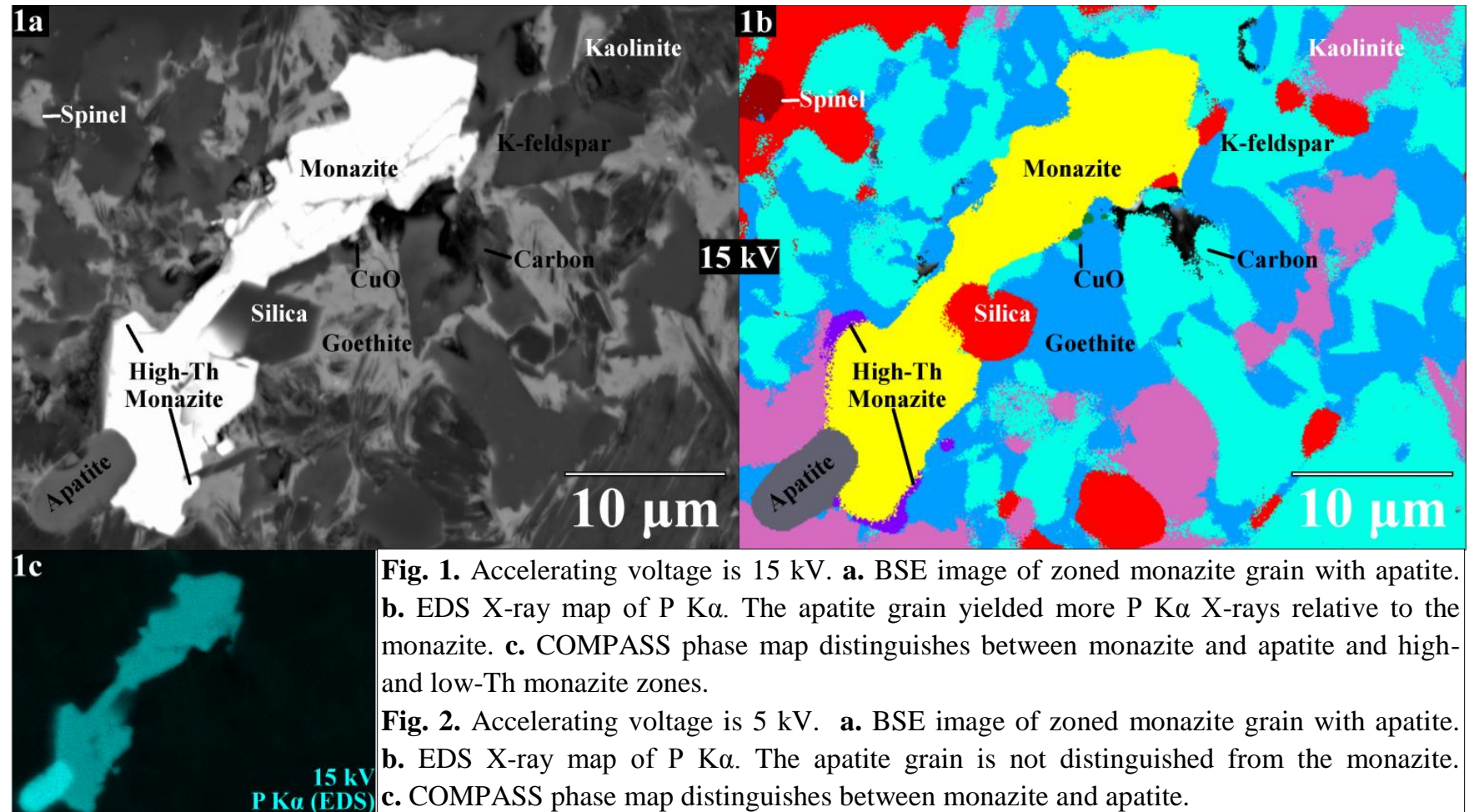

Fig. 1. Accelerating voltage is $15 \mathrm{kV}$. a. BSE image of zoned monazite grain with apatite b. EDS X-ray map of $\mathrm{P} \mathrm{K} \alpha$. The apatite grain yielded more $\mathrm{P} \mathrm{K} \alpha \mathrm{X}$-rays relative to the monazite. c. COMPASS phase map distinguishes between monazite and apatite and highand low-Th monazite zones.

Fig. 2. Accelerating voltage is $5 \mathrm{kV}$. a. BSE image of zoned monazite grain with apatite. b. EDS X-ray map of $\mathrm{P} \mathrm{K} \alpha$. The apatite grain is not distinguished from the monazite.

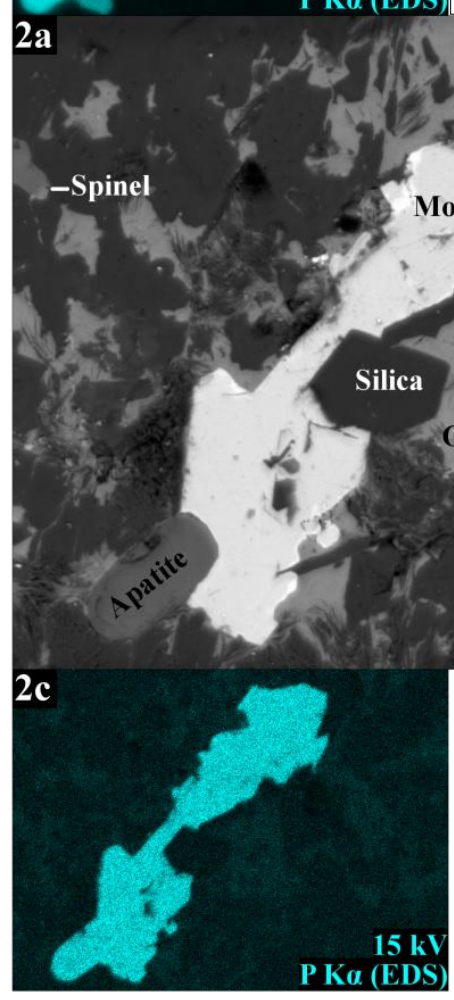

c. COMPASS phase map distinguishes between monazite and apatite.
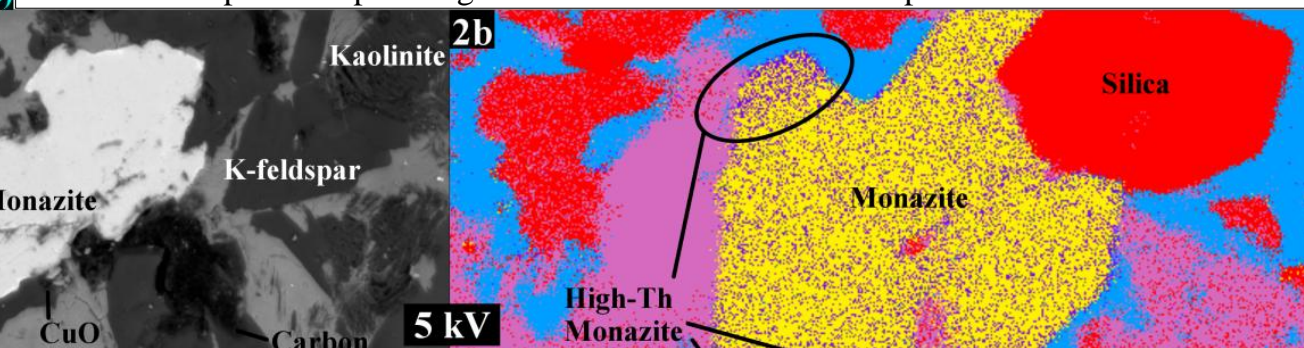

High-Th
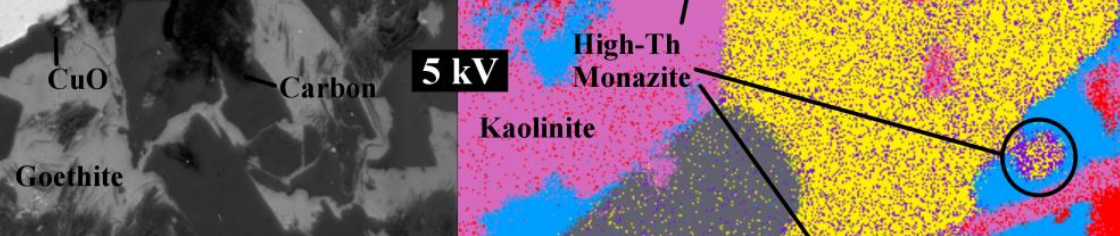

Kaolinite
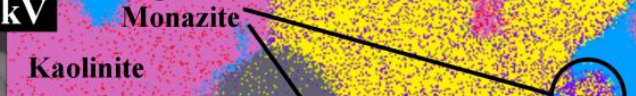

K-feldspar
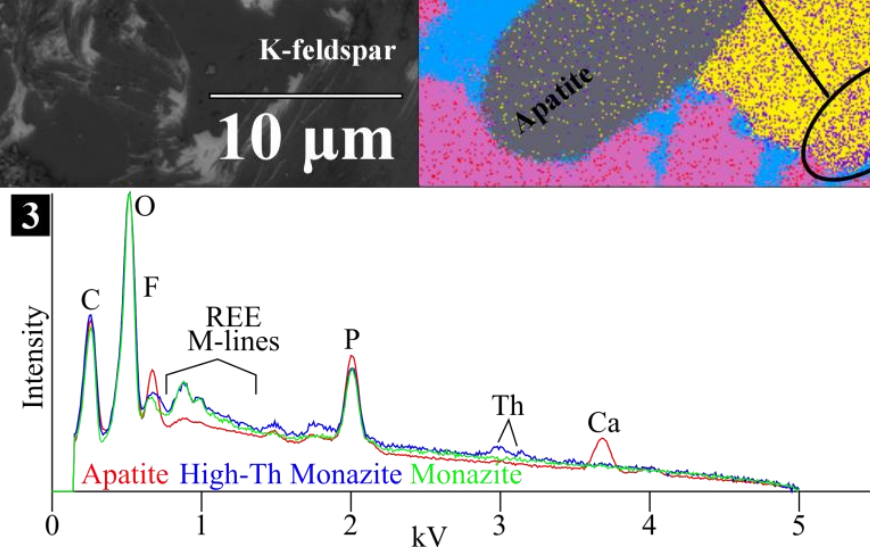

Fig. 3. EDS spectra from apatite (red), high-Th monazite (blue), and monazite (green). The vertical axis is a square root scale. 